\title{
ЯЗЫКОЗНАНИЕ
}

\author{
УДК 811.512 .37 (Калм) \\ DOI: $10.18101 / 2305-459 X-2019-4-3-9$

\section{О СОЗДАНИИ ТОЛКОВОГО СЛОВАРЯ \\ ЯЗЫКА КАЛМЫЦКОГО ГЕРОИЧЕСКОГО ЭПОСА «ДЖАНГАР»}

\author{
(C) Бембеев Евгений Владимирович \\ кандидат филологических наук, \\ старший научный сотрудник отдела монгольской филологии, \\ Калмыцкий научный центр РАН \\ Россия, 358000, г. Элиста, ул. Илишкина, 8 \\ E-mail: galdma@yandex.ru
}

Статья посвящена обзору этапов реализации задач практического и теоретического характера при подготовке Толкового словаря языка калмыцкого героического эпоса «Джангар». Материалом ТС послужили 28 текстов разновременных записей калмыцкого героического эпоса «Джангар». Словарное описание языка эпоса основывается на определенных принципах, относящихся как к описываемому объекту (эпическая лексика), так и к характеру разрабатываемого словаря (толковый). В ходе работы был использован морфологический анализатор TextAnalyzer, a создание словаря проводится в оболочке Tlex. В TC за основу был взят описательный способ толкования лексических единиц, в некоторых случаях описательно-синонимический способ. При составлении толкований использованы лингвистические, этнографические и фольклорные источники. Разработка ТС дает новые сведения о лексическом составе эпического произведения, а также информацию о том, как и в какой мере воплотилась в языке материальная и духовная культура предков современных калмыков.

Ключевые слова: словарь, толковый, Джангар, программа, лексика, семантика, словарная статья, эпос, лексикография, морфологический анализатор.

Для цитирования:

Бембеев Е. В. О создании толкового словаря языка калмыцкого героического эпоса «Джангар» // Вестник Бурятского государственного университета. Язык. Литература. Культура. 2019. Вып. 4. С. 3-9.

Калмыцкий героический эпос «Джангар» - выдающийся эпический памятник устного народного творчества монгольских народов. Структура и содержание данного произведения содержит разнородные, полистадиальные явления, которые были сформированы на основе древних архаических сюжетов тюркомонгольского мифологического эпоса, средневековых историко-эпических сказаний, содержащих черты поэтики и стилистики эпоса. Как известно лексика, в сравнении с другими уровнями языка, характеризуется наибольшей изменчивостью и непостоянством. А понимание текста эпоса во многом определяется знанием лексики. Что касается непосредственно самих монгольских языков 
Т. А. Бертагаев отмечал: «Лексикология монгольских языков является самым слабым местом в монголоведении. Если фонетика и морфология в какой-то степени исследованы, то этого нельзя сказать в отношении лексики» [Бертагаев, 1961, c. 3].

В 2014 году группа языковедов Калмыцкого научного центра РАН приступила к реализации проекта по созданию толкового словаря языка калмыцкого героического эпоса «Джангар» (далее - ТC). Необходимость создание толкового словаря обусловлена тем, что он необходим для понимания текста эпоса «Джангар», для понимания особенностей фольклорного текста. В связи с этим дается максимально подробная информация о всех релевантных свойствах каждого заголовочного слова. Для современных носителей калмыцкого языка семантика большого количества слов-архаизмов непонятна, о чем в свое время справедливо отмечал Э. Ч. Бардаев: «для современных носителей калмыцкого языка семантика большого количества слов-архаизмов стала непонятной, а то и вовсе утерянной. В связи с этим перед языковедами встает проблема - восстановить историю этих слов, найти их смысл, или по крайней мере, близкое к нему значение» [Бардаев, 1980, с. 393].

Актуальность создания толкового словаря заключается в изучение языка фольклора как особой формы национального языка. Лексемы фольклорных произведений спорадически включаются в словники обычных двуязычных словарей, тексты малых жанров фольклора, сказок и эпоса «Джангар», включены в качестве иллюстративного материала в словарные статьи. Вместе с тем эти лексемы не получают в них полного и адекватного описания, поэтому толковый словарь, построенный исключительно на материале эпоса «Джангар» в соответствии единой с концепцией и принципами, призван заполнить одну из лакун калмыцкой лексикографии.

В настоящей статье нами описаны основные этапы составления толкового словаря языка калмыцкого героического эпоса «Джангар».

На начальном этапе была осуществлена работа с источниковой базой. Материалом толкового словаря послужили 28 текстов разновременных записей калмыцкого героического эпоса «Джангар» ${ }^{1}$, которые объединены в репертуарные циклы или представлены отдельными песнями. Для удобства мы решили разделить их по временному критерию:

I. Ранневременные записи: Малодербетовский цикл (3 песни, записаны в 1862 году), Багацохуровский цикл (3 песни, записаны в 1854-1862 гг.);

II. Записи первой половины XX века: Эпический цикл сказителя Ээлян Овлы (10 песен, магтал, записаны в 1908 году), Эпический цикл сказителя Мукебюна Басангова (6 песен, записаны в 1939 году), Эпический цикл сказителя Давы Шавалиева (4 песни, магтал, записаны в 1939 году), песня из репертуара Бадмы Обушинова (1 песня, записана в 1901 году);

III. Поздневременные записи: песня из репертуара Насанка Балдырова (1 песня, записана в 1966 году).

Затем была разработана структура словарной статьи, в которой отражается максимально подробная информация каждого заголовочного слова. В структуру

\footnotetext{
${ }^{1}$ В КалмНЦ РАН создается «Свод калмыцкого фольклора», который включает в себя репрезентативные песни эпоса «Джангар» и их переводы.
} 
E. В. Бембеев. О создании толкового словаря языка калмыцкого героического эпоса «Джангар»

словарной статьи включены следующие элементы: входное заголовочное слово, абсолютная частота употребления лексической единицы в текстах эпоса, транскрипция, грамматические и стилистические пометы, объяснение их значений толкования и примеры использования слов в данном значении, фразеологизмы, дериваты, сложные слова, коллокации. На первом этапе планировалось создание одноязычного толкового словаря, но в ходе работы было принято решение в целях сохранения и ревитализации языка, снабдить слова и толкования переводом на русский язык. Это в значительной мере увеличило объем работы, но с практической точки зрения стало понятно, что такой шаг повысит репрезентативность словаря, а также расширит его использование.

На первоначальном этапе группа решила сосредоточиться на подаче слов тематическими гнездами по частям речи. Этот подход предполагает сохранение описания фольклорной картины мира в структурированном порядке и разделение ее на фрагменты, которые находятся друг с другом в сложных отношениях. Забегая вперед необходимо отметить, что этот принцип создания толкового словаря, в силу ряда причин, был впоследствии заменен на традиционный метод, который заключается в составлении и редактировании по буквам, алфавитной разбивке единиц, включенных в словник. В ТС за основу был взят описательный способ толкования лексических единиц, в некоторых случаях описательносинонимический способ, так как, на наш взгляд, это одни из лучших видов толкования значений слов, которые наиболее полно и точно раскрывающих значения заголовочных слов.

Эффективность и значимость работы определяются необходимостью внедрения новых технологий. Одним из таковых является использование морфологического анализатора TextAnalyzer, с помощью которого осуществляется автоматический анализ корпуса текстов эпоса «Джангар». Данная программа позволяет оперировать большим объемом информации и анализировать лексические единицы в их контекстуальных связях. Таким образом, путем обобщения достаточно широкого иллюстративного материала выявляется типовая сочетаемость, которую возможно представить в виде обобщенной характеристики позиций, чаще всего реализуемых в окружающем лексическую единицу контексте. Основными задачами электронной программы TextAnalyzer являются морфологический и лексико-семантический анализ текстов на калмыцком языке, а также частичное снятие омонимии [НККЯ - электронный ресурс]. При обработке корпуса текстов эпоса «Джангар» парсер однозначно разобрал около 70-75\% токенов, а по оставшимся 15-20\% текстового материала дал множественный результат анализа. Поэтому была проведена работа по ручному разбору 13777 словоформ. Благодаря автоматическому разбору в программе TextAnalyzer, толковый словарь снабжен информацией о частотности употребления слов, в которой представлена частотная характеристика, информация о словах или определенной группе лексики, более распространенной и менее частотной. Частотность отражает степень употребления слов в эпосе, а также выявляет специфические особенности языка. В Частотном словаре за элемент словника принимается лемма, которых насчитывается 3858 единиц [Бембеев, Куканова, Каджиев, 2014]. 


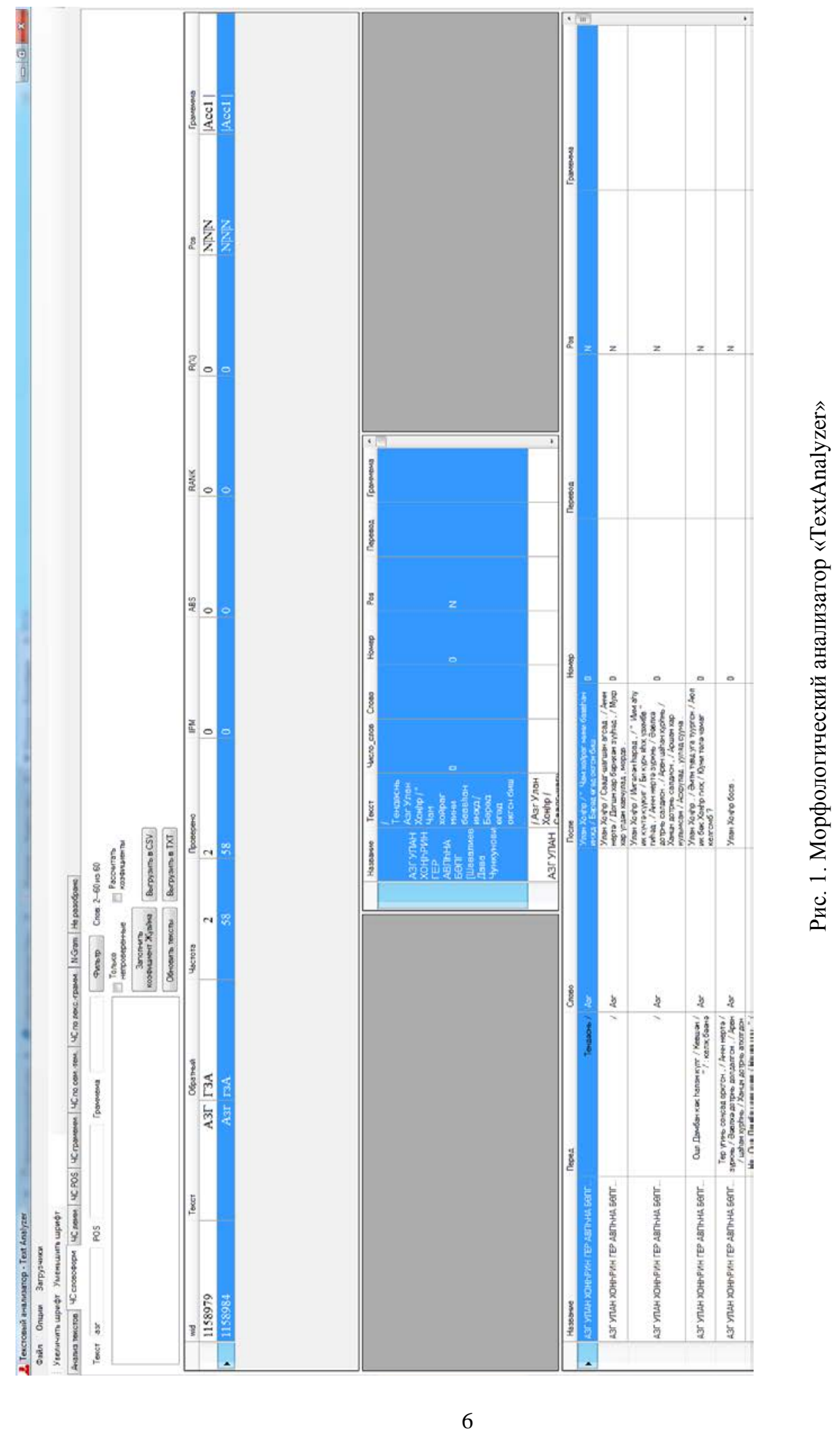


E. В. Бембеев. О создании толкового словаря языка калмыцкого героического эпоса «Джангар»

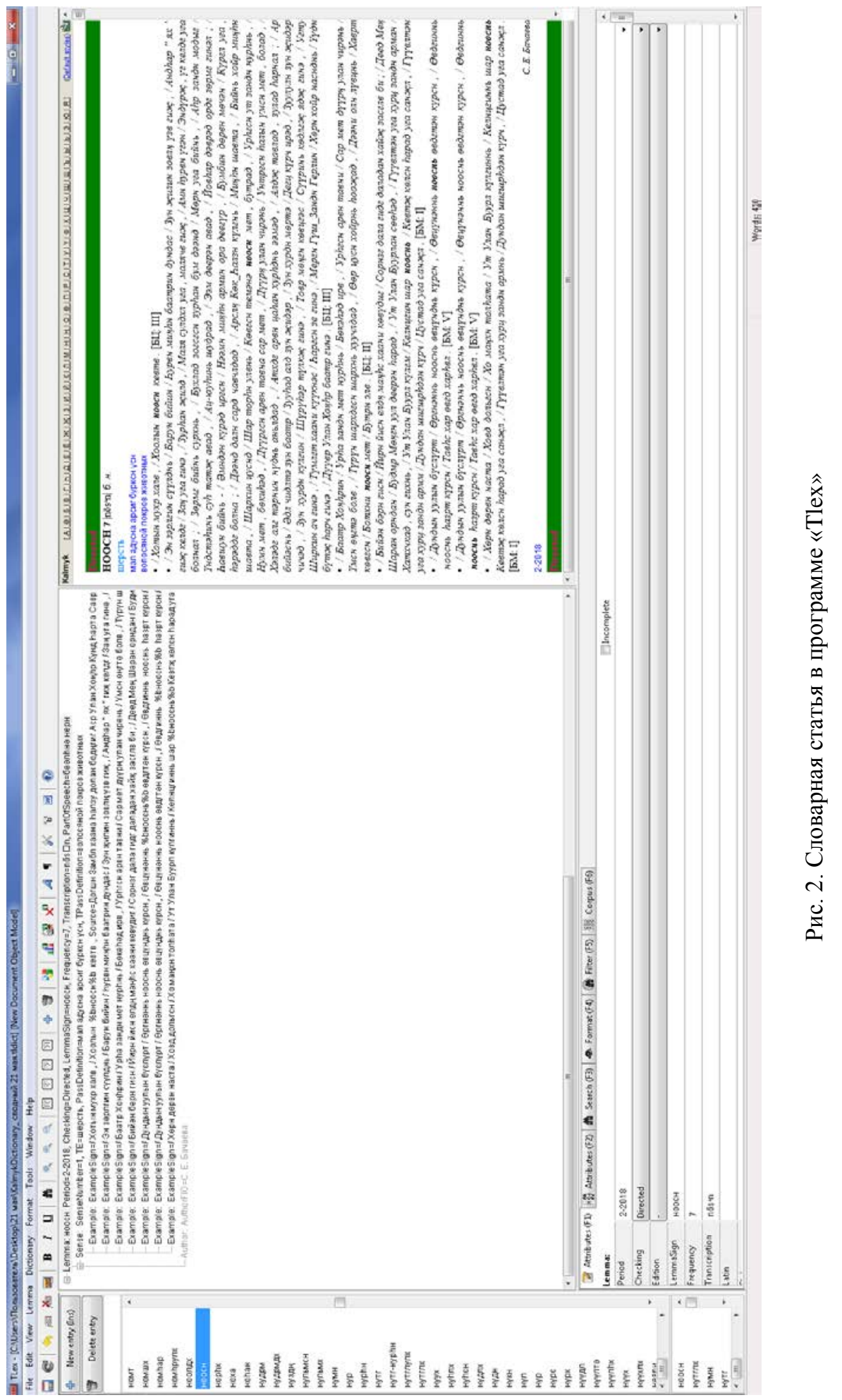


Разработка словарных статей ТС проводится в специализированной программе «Тleх», где представлен каждый тип лексикографической информации в порядке, который был заложен в структуру программы в соответствии со строгой стандартизацией и формализацией описания лексических элементов. Словарная статья представляется в следующей структуре: заголовочное слово и метатекст (в котором даются основные характеристики лексемы, толкования). Основным критерием включения лексемы в ТС является его фактическое использование в текстах «Джангара». В электронную базу «Тleх» каждой словарной статьи включены все примеры, которые были разобраны с помощью программы TextAnalyzer.

При составлении толкований использованы лингвистические, этнографические и фольклорные источники. В эпосе выявляются лексемы, относящиеся к безэквивалентной лексике, которая требует полного детального описания. В acпекте создания толкового словаря калмыцкого героического эпоса «Джангар» лексемы также рассматриваются с точки зрения их внутренних смысловых отношений.

Таким образом, разработка толкового словаря дает новые сведения о лексическом составе калмыцкого языка, а также о том, как и в какой мере воплотилась в языке, в частности ее лексико-семантической системе, материальная и духовная культура предков современных калмыков. Он станет ценным материалом не только для лингвистов, фольклористов, а также для тех, кто интересуется языком и культурой калмыков.

Исследование проведено в рамках государственной субсидии - проект «Устное и письменное наследие монгольских народов России, Монголии и Китая: трансграничные традиции и взаимодействия» (регистрационный номер АAАA-A19-119011490036-1).

\section{Литература}

1. Бардаев 1980 - Бардаев Э. Ч. Некоторые вопросы изучения лексики «Джангар» // «Джангар» и проблемы эпического творчества тюрко-монгольских народов: материалы Всесоюз. науч. конф. (Элиста, 17-19 мая 1978 г.). М.: Наука, 1980. С. 390-395.

2. Бертагаев Т. А. К исследованию лексики монгольских языков. Опыт сравнительно-статистического исследования лексики бурятских говоров. Улан-Удэ: Изд-во БКНИИ, 1961. $160 \mathrm{c}$

3. Бембеев Е. В., Куканова В. В., Каджиев А. Ю. Частотный словарь современного калмыцкого языка: правила анализа текстового материала // Вестник Калмыцкого института гуманитарных исследований РАН. 2014. № 3. С. 128-141.

4. Национальный корпус калмыцкого языка (НККЯ) [Электронный ресурс] // URL: http:kalmcorpora.ru (дата обращения: 12.04.2018).

\section{ON THE CREATION OF AN EXPLANATORY DICTIONARY OF THE KALMYK HEROIC EPOS “DZHANGAR”}

\section{(C) Yevgeniy V. Bembeev}

Ph. D. of Philology, Senior Researcher, Department of Mongolian Philology

Kalmyk Science Center of the Russian Academy of Sciences

8, Ilishkina Str., Elista, 358000, Russia

E-mail: galdma@yandex.ru 
The article is devoted to an overview of the stages of the implementation of practical and theoretical tasks in the preparation of the Explanatory Dictionary of the language of the Kalmyk heroic epos "Dzhangar". The material of the TS was 28 texts of various records of the Kalmyk heroic epic "Dzhangar”. The vocabulary description of the language of the epic is based on certain principles relating both to the described object (epic vocabulary) and to the nature of the dictionary being developed (explanatory). In the course of work, the TextAnalyzer morphological analyzer was used, and the dictionary is created in the Tlex shell. In the TS, a descriptive way of interpreting lexical units, in some cases a descriptivesynonymous method, was taken as the basis. In compiling the interpretations, linguistic, ethnographic and folklore sources were used. The development of the TS provides new information on the lexical composition of the epic work, as well as information on how and to what extent the material and spiritual culture of the ancestors of modern Kalmyks was embodied in the language.

Keywords: dictionary, explanatory, Dzhangar, program, vocabulary, semantics, dictionary entry, epic, lexicography, morphological analyzer. 